\title{
An Enhancement of TOE Model by Investigating the Influential Factors of Cloud Adoption Security Objectives
}

\author{
Md Yeahia Bhuiyan, Siti Hajar Othman \& Raja Zahilah Raja Mohd. Radzi \\ Faculty of Computing \\ Universiti Teknologi Malaysia \\ 81310 UTM Johor Bahru, Johor, Malaysia \\ yeahiabhuiyan@gmail.com, hajar@utm.my, zahilah@utm.my
}

Submitted: 09/06/2018. Revised edition: 02/04/2019. Accepted: 04/04/2019. Published online: 30/05/2019

DOI: https://doi.org/10.11113/ijic.v9n1.192

\begin{abstract}
Cloud computing (CC) is a future technological trend for technological infrastructure development. And it is growing strongly as the backbone of industrial future technological infrastructure. As CC service has a lot to offer, it also has some major downside that clients cannot ignore. For $\mathrm{CC}$ service adoption, the potential candidates are SMEs but due to lack of resources, experience, expertise and low financial structure scenario $\mathrm{CC}$ can be most helpful. $\mathrm{CC}$ faces a major issue in term of cloud security, an organization doesn't understand the cloud security factors in the organization and data owner doubts about their data. In the research paper, an investigation on the cloud security objectives to find out the influential factors for cloud adoption in SMEs by proposing an enhancement of Technology-Organization-Environment (TOE) model with some positive influential factor like cloud security, relative advantages, cost saving, availability, SLA, capability, top management, organizational readiness, IS knowledge, malicious insiders, government regulatory support, competitive pressure, size and type. Some negative influencing factors like technological readiness, cloud trust and lack of standards in cloud security. Data were collected by questionnaires from a selected IT company based on SaaS and public cloud. Case study method has been used for validating the enhance TOE model. The IBM Statistics SPSS v22 tool was used for data analysis. The results of data analysis support the enhancement as well as all the proposed hypotheses. In summary, the results of the analysis show that all the enhancement factors were found to have a significant cloud security influence on adoption of cloud computing for SMEs.
\end{abstract}

Keywords-Cloud Computing (CC), Small and Medium Enterprise (SMEs), Cloud Adoption, Software-as-a-Service (SaaS), Cloud Security

\section{INTRODUCTION}

We come to know from NIST (National Institute of Standards and Technology) that CC is a worldwide, suitable, anytime available network which can share the data and configuration of the computing properties (like desktop, server, software, apps, data storage, and services) anywhere in the world with remote connection with slight administration effort or with any necessity of communicating with service provider [34].

$\mathrm{CC}$ is now highly acknowledged technology that causes cloud providers to introduce many cloud services in the market. Though there are many advantages of $\mathrm{CC}$ with its quick evolution, it faces many issues in terms of privacy, trust, storage, network, malicious insider, user and mostly security issues [40]. These are so important factors that cloud customers should keep in mind while negotiating the terms of service with the provider before taking or while using CC. CC reduces the cost of purchasing and maintaining IT infrastructure for the businesses that use CC. It also provides better flexibility regarding how computing resources can be bought and utilized.

The limitless scalability, resources sharing elasticity and high level of computerization CC is making the future Internet technology. The cloud environment is growing swiftly day by day but at the same time it worries about its security, privacy and trust for data and applications on the hosted situation. There are many providers available to provide $\mathrm{CC}$ for consumers and this is also a great situation for customers $s$ to make trust on any provider that will provide the best service 
according to the requirements of customers s. This is the most important decision-making time when customers s cannot achieve the best from CC because of the lack of knowledge, training, competitive business pressures and provider reliability issues [39].

Organizations are still concerned about the security, losing control and other disagreeable results over their data which is affecting the decision making on the migration of the service, software, server or data to the cloud [41]. Besides, organizations are typically focused in moving to some of their systems in the cloud because of the difficulty in adoptionrelated applications, security concern, less understanding the process as well as the lack of information security (IS) knowledge about agreements [5].

The purpose of this study is to understand the determinants of cloud adoption in small and medium enterprises (SMEs). It seeks to investigate whether the determinants of cloud adoption influential factor in cloud security. For this purpose, we develop an enhance research model of the technological, organizational and environmental (TOE) [51].

\section{II.LITERATURE REVIEW}

\section{A. Background of the Problem}

Organization needs to set up infrastructure for the data and use resources but again using CC will bring up the best offers for SMEs like no physical setup and they need to pay up to how much they will use [29]. This helps in a big way of reducing financial cost for both Small as well as medium enterprises. Among all the great gorgeous offers that $\mathrm{CC}$ is offering, SMEs are really concerned about the thought of moving current system to the CC [33].

From a recent research that was published in Forbes 2017, saying about cloud adoption in Information Technology that is $80 \%$ of all IT budgets, will be considered for cloud solutions and applications within a year [19]. The most demanding technology in $\mathrm{CC}$ is security that always necessary to take account whenever they think about cloud adoption. Security is the most important factor to delay $\mathrm{CC}$ adoption for cloud customers.

As cloud storage is hosted by third party which is stored in virtual pool of storage online network model, cloud providers provide the storage service. As clients want to keep their data in the cloud they need to buy or lease the storage with the capacity. As per customers requirement, vendor provides the storage and functionality that also take care of the background systems. For the SMEs, sustainability matters always come to the matter of reliability and availability of the service. As its crucial for the day to day operation, its mandatory for availability of application and other important data in time. And reliable to the provider support and error correction services. Sometimes vendors fail to do so, in overall that gives customers business a negative impact [33].

As in public clouds, SaaS users use the service online and by using Internet browsers. Because of Internet browser plugin and many bugs attacker can get access to the internet, web and over service. Hacking and injecting suspicious code in the SaaS system, can break the isolation wall of cloud security [17]. Major security factors like data storage, malicious insider, user and malware, which makes cloud more vulnerable for the SMEs business as well as security perspective.

Some research paper shows, working with the TOE model for Technological cloud adoption is more influential than others as because TOE model theory has been applied individually and successfully to several studies for the adoption of innovation in cloud and technology. There have been numbers of literature, exploring the use of innovative technologies in the past that combine the TechnologyOrganization-Environment (TOE) model better for the organizational perspective [37]. On the Low [30] paper is focused on the management and technology but lacking on the security, support and cost factors. The Chong [45] paper worked on relevant advantages, compatibility and top management but it doesn't have data about a technological scenario like security, technical readiness, cost problem. There are some other researches which combine the TOE and DOI model, like on the Bose [43] research shows the process to make adoption decision based on organization type, size and regulatory management these papers don't have strong technical functionality. Such approach has never been exploiting in CC readiness assessment. Most of the previous researches have a leaking on privacy, security and service level agreements. In TOE model, to focus on the environmental context of technology adoption and better to explain intra firm technology adoption [50]. The main advantages of TOE model are doing the support and theoretical aspects for our research.

Through this paper, it will provide investigation and analysis on the cloud computer to serve level agreement and security as well as background on IT CC adoption. Also, provide related research on the technology organization environment (TOE) model security objectives. Then, we describe the theoretical foundations and advantages of the TOE model focusing mainly on the technology and organizational factor as well as some environmental and control factors for improving the consumer view over the IT $\mathrm{CC}$, and security. Then we will validate this outcome with the questionaries' and the case studies. Thus, the research objectives here are:

1. To investigate the Technology Organization Environment (TOE) Model.

2. To propose enhance TOE model for cloud adoption in security perspective.

3. To validate the enhancement of TOE model for identifying cloud adoption influential security factor by following case study.

As After going through lot of previous research we finally selected the factors which we like to focus on this research for assessing cloud computing, SME and security. By means of investigating cloud adoption we selected Al and Salim [2] 
TOE model (Fig. 1). In this paper its mostly focus on the cloud adoption, security for Australia SMEs. This paper use TOE model for investigate on the cloud adoption influential factors. This paper missing on details security issues. As its only work on the general security concerns, related issues, privacy risk. And this paper future work motivates this research paper in many ways. So, we finalize this TOE model to enhance in terms of cloud security factors. Finally, we will be focusing on this context in details to indicates it on the case study phases. Later portion we will be viewing the advantages from previous research on TOE model and propose an enhancement TOE model for fulfill this research gap appropriately.

Besides, the focus will be more on the technology and organization factor. For environmental factors will add more future for the enhancement. In this enhancement, we will also introduce two (industry size and type) major control variables which will work as moderator to enhance the cloud adoption success.

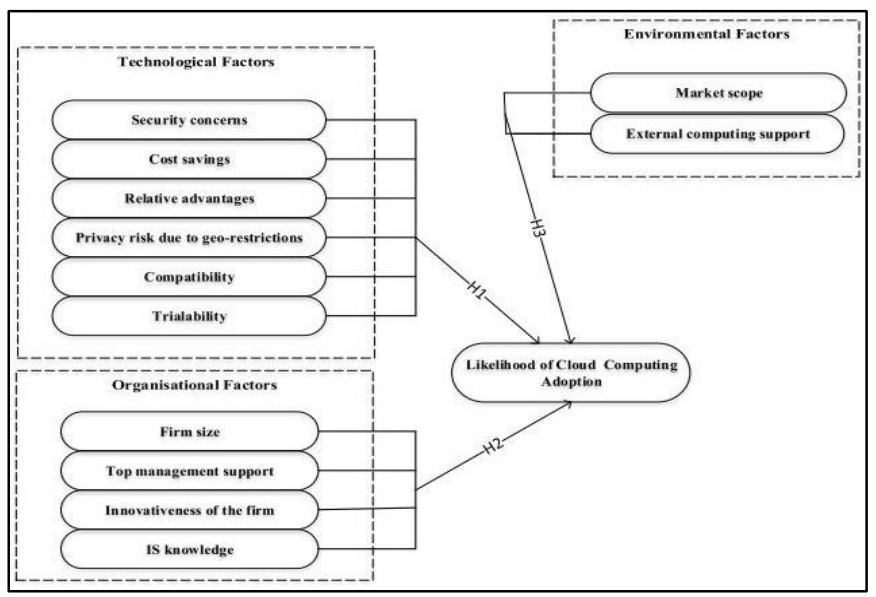

Fig. 1. Previous TOE model [2]

\section{B. Exiting Work on Cloud Computing and Security}

This section will highlight the literature review of the existing works. The projecting aspect of the review includes the arrangement of the salient features of the works as opposed to their limitations. The arrangement of prominent features and limitations of the existing works provides an insight into the knowledge gap that is prevalent in the field of $\mathrm{CC}$ security research. $\mathrm{CC}$ is a source for providing a flexible resource. It is an on-demand computing that gives shared resources or applications to the consumer of the cloud [54]. $\mathrm{CC}$ is an adaptable source of resources. Cloud environment attracted many companies to implement cloud environment and make it available for the users to use its elastic availability of applications. Many applicants have been migrated to cloud platform. Through advancements in computing world, it is nearly possible that computing will become the most necessary utility of daily life [38].
Kalaiprasath paper use a comprehensive study to review the potential threats against cloud security and policies. They explain all the security issue with the data in focus [23]. Chang and Ramachandran propose on their paper a CC adoption framework (CCAF) to demonstrate the data security components issues and multi-layer security protection plan to protect data from attacker. They also provide review about data storage in cloud and the vulnerability. This study lacking in depth data security issues when it's come to cloud storage in cloud environment [11]. Beulah paper explain with survey the difficulties cloud customers face while adopting cloud in terms of various attackers. What security issue are available mostly on the data, network and applications. This paper limits on focusing the privacy risk, cost, trust or security standards [8].

In the Carvalho paper mainly worried about the safety issue for client's data. And he said security and agreements with vendors needs to use to overcome this concern [10]. So, it will be guaranteed the service availability and other facilities of service as promised. The main problem shows in this paper is loss control over cloud and structure. This paper used systematic mapping methodology to solve issue by implying management in to the security to full fill research gaps. This paper does not focus on deploying the model in the public cloud environment and poor evaluation of security results not parade of security issue.

$\mathrm{A}$ in the trust matter Ahmed paper showed in his paper lack of trust can be very disturbing for data and increase weakness factors [1]. The data owner gets a lot of issues with the cloud as it shows a challenging factor also for the cloud provider. Cloud storage is not known to location by the data owner as makes more untrusted issues. This paper more focus on the data problems but lacks in security and quality of service issues.

Next paper Tariq is presented the IT governance model work to support for administrative cloud challenges. They use COBIT framework for methodology to solve the problem [49]. This paper has some security factors which is not details but as their future work also give useful guidance for motivation the research.

For security perspective, Chawngsangpuii paper claimed to solve the cloud security issue by focusing on the influential factor. They show cloud challenges and security objectives and challenges [13]. According to the previous paper, almost all existing work don't offer holistic method to discuss the cloud security. The next paper discusses about a SaaS and CC and cloud advantages. This work fills this gap by proposing a fresh security and agreement-based resource management system designed after analyzing requirements of SaaS in Clouds. Case study method use by researcher for this paper to illustrate the SaaS in cloud in real imprecation [29].

There are some other papers, also conduct research in CC security. In all the papers mostly, who worked on cloud security with different objectives, have no focus on the problem gap we are working on. Some papers talk about security, some talk about data protection issues and challenges $[13,9,38,46]$. 


\section{III.RESEARCH METHODOLOGY}

The purpose of exploring the impact of advantages of Technology organization and environment (TOE) factors on SME adoption of CC security agreements services. In order to assemble all the pertinent data for the research, it is important that the operational framework is created which will ensure that every activity and tasks of the project are accordingly followed and completed (Fig. 2 shows).

\section{A. Phase 1 (Primary Study, Review and Investigation)}

The initial planning phase is the beginning of the project. This initial phase started by reading the article, journal in the area of CC, cloud security and cloud adoption model by TOE model. This phase 1 includes identifying and researching from the previous study. This helps to improve better understanding within the security in cloud adoption domain. Many techniques and approaches are identified during this analysis phase. Another important step before conducting research experience on cloud adoption is to find the suitable case study for analysis purposes. The objectives of the project were analyzed and defined according to the problem statement. Also, the scope of the project determined to represent the projects inside borderline then research work was conducted on the problem background of the project to choose the right methodology of the project.

\section{B. Phase 2 (Research Design)}

This study applied a case study method design to determine cloud security attributes that influence the adoption of CC. The research was conducted using phases- 2 which will serve the research objectives 2 such as, to adopt mainly on technological and organizational benefits and propose to enhance TOE model with control variable for security in cloud adoption.

\section{Phase 3 (Research Analysis)}

This phase-3 is most important part of the research. After proposing an enhanced model based on TOE model we did analyze the data so that we can claim the enhancement have contributed the CC adoption facts. For evaluating the model, we use a questionnaire and case study from real scenario. Later, we evaluate the result based on questionnaire results by using SPSS statistics tool and correct this model and by case study, we validate the model. In this phase, we will cover the objective 3 purely like, questionnaire and case study methodology, validate enhance model effectiveness and result of the enhancement TOE model.

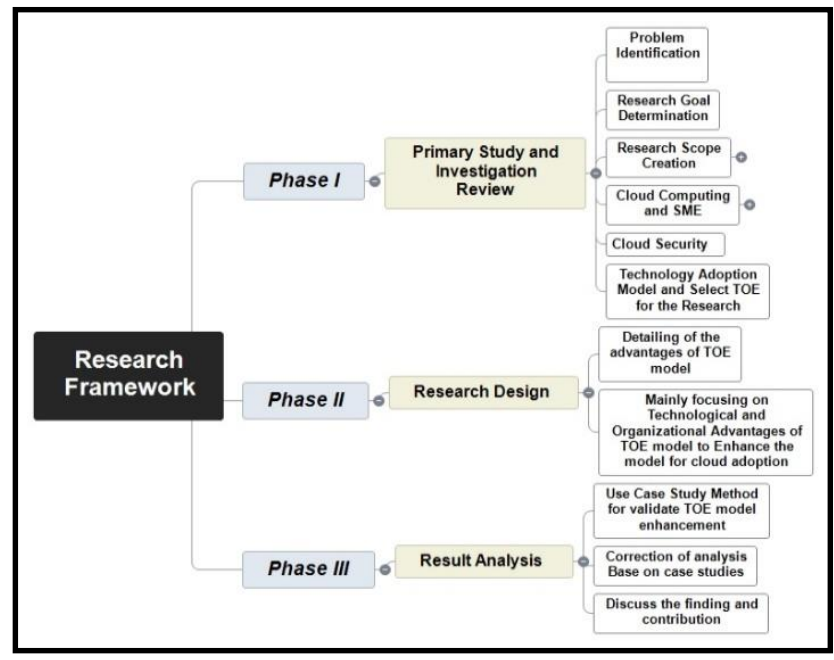

Fig. 2. Research Framework

\section{Case Study Method}

In this study, we will be using case study method to investigate the outcome, so there are some steps we will be following through the research, after getting the result, it can be easily find out the main influential factors in cloud adoption. By conducting in research on previous paper and ready questionnaire analysis for real cases for the IT company SMEs and through analysis and enfolding literature, the researcher initial concepts, security concept constructs, a set of preliminary enhancing context are deterministically influencing cloud adoption or not and discovering the real security influence objectives for the adoption.

\section{E. Correction of Analysis Base on Case Studies}

In the analysis stage, we realize the result through the case study method. So, from the result analysis from SPSS statists, we can understand that which factors of security in the TOE model is most successful than other and which factor have the more influential feature so that we can make more accurate enhancement of the TOE model.

\section{ISSUES AND CHALLENGES}

SMEs are got small amount of human resource as well as low in skills and experiences exports to enrich in technological aspect. Still, SMEs are universally making more influence in business sustainability and growth. In terms of cost, they need to be more focus on reduce expenses and more focus on the profit scenario. Motionless with all the challenges and issues in SMEs they are seems to be getting success in the current competitive word in terms of implementation phase. As cloud give then a certain limitation on the customization for meeting customer's needs. As customers do not understand properly the security concern don't have any expatriates in SMEs [27]. As Hussein and 
Khalid paper showed in there survey study cloud security concerns [22]. They presented security issues and challenges in cloud we are faced up to 2016.

From all the three models, most popular is SaaS for SMEs and its can be deployed and hosted remotely to the cloud. All the remote work done by internet as this is one of the major part where threat come for cloud. As its helps SMEs financially and remove operation hassle dynamically. As in cloud, you don't need to install outside application, just need internet to use the applications, that's why SaaS model swiftly growing with the customers requirement. In place of requirement, they are getting more day by day as SaaS is not getting security enough. Besides, there are countless security issues have already come to be focused. By the way of accessing the SaaS, it uses the web technology at its developed by the programmer and its update its plugins, addons, language processors frequently. In place of web get vulnerable to attack as its provider already facing issues. From customers s' point of view, it's hard to recognize data is secure to the cloud or not [14].

In scenario, customers $\mathrm{s}$ rent the service from the vendor and it's available through the web interface and internet, then clients need to configure the initial phase of configuration and they need to monitor the progress, actions and usages properly. In the cloud interfaces, the administrator has the access write still this is the main point where attacker do search for loophole. As every user have different access id and applications also have some issue so they use this for injecting the attack on the cloud environment. Also cloud fronted use the administrator management console VMs as its access was done remotely from internet so there always an option for loss of security like injection and cross-site scripting (XSS) [17].

Aldossary and Allen paper shows about customers and storage security. Cloud customers use files and rapidly update some time rarely updating the files, its storage by SaaS. Therefore, it is strongly recommended for the data that it needs to be secure and correct. As its remote access to the service, it's outsourced which is insecurity and undependable. Data may be lost or errored by the administrative problem some time data corrupt while restore the incorrect backup files. Attacker can use this opportunity to take advantage and take control over the data [3].

In the Fernandes paper use survey methodology to provide the security challenges in user frontend. In public cloud, there are many issues with SaaS and its user frontier. In SaaS service user use online and browser facility to access and maintenance like administrative work in the cloud and its use un-security browser tools as it's have plugins, add-ons which is always a great susceptible point for user and attraction point for attacker. Hacker can use those opportunity to inject bad codes inside the programs to get the cloud access and user write [18]. In this paper also talk about the data storage and malware, which makes cloud more vulnerable to the attackers.

Cloud security always face challenges because of another major issue is capability according to Dillon and Vossen. As SMEs are not well sufficient for any changes any time as they don't have huge resources. They need time and effort and some time they need time to come up with the cloud. And they have lack of training, experience and understanding so for cloud security it's really alarming in many cases [31]. In make case they face issue with the inside people can call malicious insiders who can hurt big time for SMEs. So, it's one of the major issue for the cloud security factors $[35,44,16]$.

In the SMEs scenario, they always try to maintain steadiness in between government legal compliance and the technological adoption. As cloud lakes in terms of standards, SMEs feel unenthusiastic about cloud adoption and its legal regulatory and compliance pressure issues. SMEs worried about in case any breach and data auditing case they need legal action so for that they always need to understand and implement proper way by takin support from government regulatory factors [24].

All organizations care about security challenges at the same time it is one of the substantial blockades for cloud adoption. This leads to problem between customers and provider because of insecurity circumstances [36]. As some researcher said CC is really a big area, so in it there are too many components and agreement as well as support, service factors are included, this makes clients mode confuse on the decision making as most of the decision makers, not from IT background they don't have good knowledges, most of the time they need help from experts. In this $\mathrm{CC}$ it's under on demand factor can be more confusing if the time-sharing system and inconsistence technological adoption counts. This will have a big negative influence in $\mathrm{CC}$ adoption.

In the $\mathrm{CC}$ environment, all the customers s always has doubts about the cloud provider and the service they are offering. they feel insure to hand over there most important asset (data) to someone who they don't really understand. So, for cloud adoption trust is a major concern for both parties. As in cloud data owners don't know here the data stored and how securely or what security countermeasures they are taking to provide security as now a day's cybercrime is increasing alarming rate [36].

\section{JUSTIFICATION ON SELECTED APPROACH}

We know TOE frame work is one of the popular technological adoption model as its consider organization factor with technological development. From previous research we ca see there are many successful studies is conducted by TOE model $[12,25,52]$. As most of the security context TOE model is used but it's also can use technological adoption in cloud security factors.

This model is the most useful in investigating technology adoption for not only the organization aspects but also for technological factors. In Alshamaila paper also focuses on the five attributes and some additional innovation factors which helped the investigation stronger outcome. They talk about cost, security factors mainly [4]. In addition, for environmental factors they also include the government issues. Many previous papers indicate that TOE model always perceives good evaluation in view of appropriate factors of considering cloud adoption. Therefore, TOE model offers the 
technological adoption in innovation along with the cloud adoption complex factors and give a holistic conclude view to develop the business more strongly and successfully with time and trends $[41,45,28,58]$.

Using TOE model, we can more focus on the $\mathrm{CC}$ adoption and security factors, therefore we used TOE model and its advantages to enhance TOE model for fulfilling the research gap. Using TOE model, we can more focus on the $\mathrm{CC}$ adoption and security factors, that is why, we will use TOE model and using its advantages to enhance TOE.

\section{RESEARCH DESIGN}

After going through a lot of previous researches we selected the factors which we like to focus on the research for investigating $\mathrm{CC}, \mathrm{SME}$ and security. By means of investigating cloud adoption, we selected Al and Salim [48] TOE model. In this paper it mostly focuses on the cloud adoption, security for Australia SMEs. This paper uses TOE model for investigating on the cloud adoption influential factors. This paper is missing on details security issues. As it only works on the general security concerns, related issues, privacy risk. And this paper future work motivates the research paper in many ways. So, we finalize this TOE model to enhance in terms of cloud security significant factors. We worked on the contexts which will be more influencing the cloud adoption. Finally, we will be focusing on this context in details to indicates it on the case study phases. At the later portion, we will be viewing the advantages from previous research on TOE model and propose an enhancement TOE model to fulfill the research objectives and goal appropriately (Fig. 3).

\section{A. Technological}

In this technological context, it discusses about the inner details and exterior knowledges appropriate to the cloud Security for SMEs. This technological context focuses on

adoption of cloud innovation will pretentious by its apparent appearances including Cloud Security Concern, Related Advantages, Cost Saving, Availability, Service Level Agreement(SLA), Technological Readiness, Trust, Capability, Lack of IT Cloud Standards. These advantages of the technology always predicable as the most crucial factor for cloud adoption [17, 2, 32]. When assumed benefits are more, there are more chances for the organization to achieve success. To achieve this the organization will allocate more resources for IT administrative, economic factors and core technical business factors to implement in the scheme [48]. We will be discussing the technology context as Fig. 2 shows.

H1: Cloud Security will have negative influence on cloud computing adoption.

H2: Related advantages will have positive influence on cloud computing adoption.

H3: Cost Saving will have positive influence on cloud computing adoption.
H4: Availability will have positive influence on cloud computing adoption.

H5: Service Level Agreement will have positive influence on cloud computing adoption.

H6: Technological Readiness will have positive influence on cloud computing adoption.

H7: Trust will have positive influence on cloud computing adoption

H8: Capability will have positive influence on cloud computing adoption.

H9: Lack of IT Cloud Standards will have negative influence on cloud computing adoption

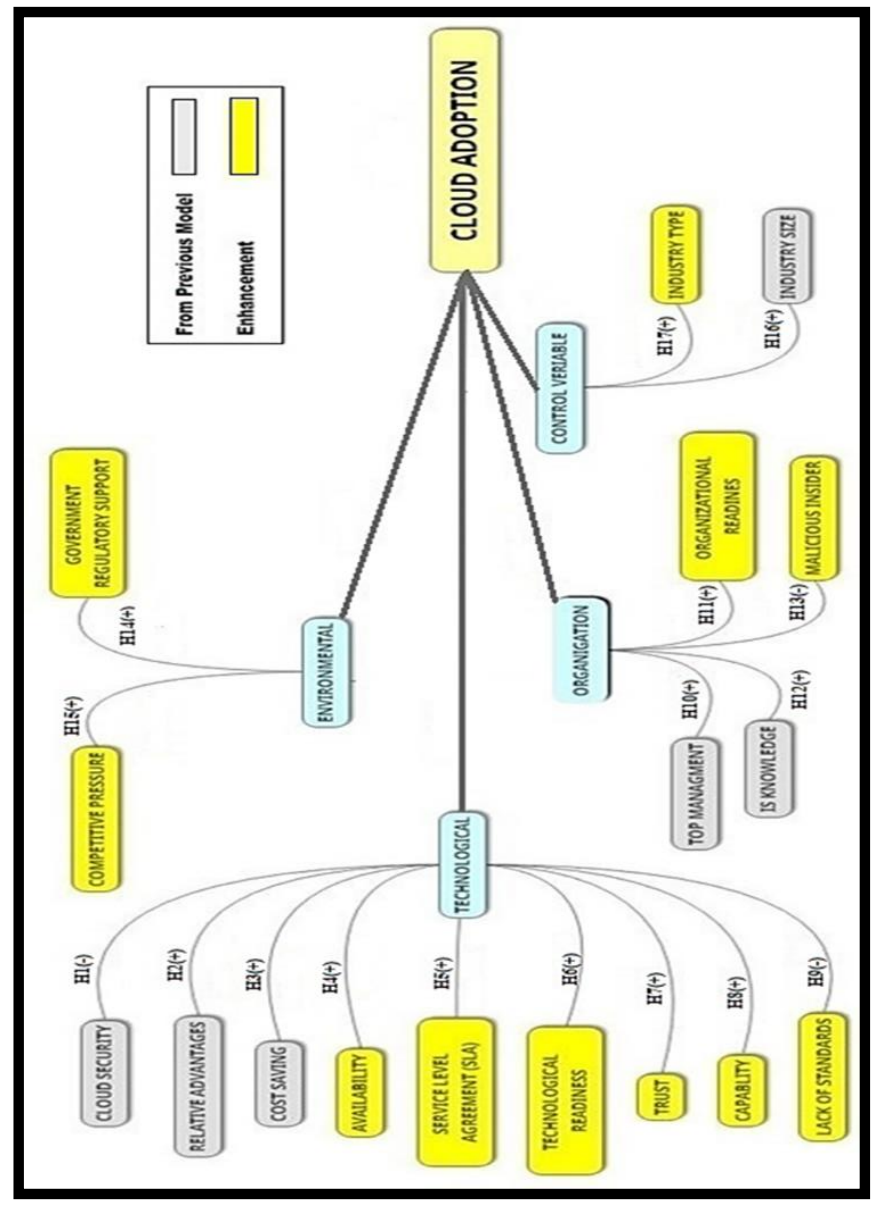

Fig. 3. Propose Enhance of TOE model and Hypothesis

\section{B. Organizational}

It is significant for any enterprises to understand the CC adoption isn't only a specialized technological issue, but at the same time is an authoritative issue which comprise of clients, costs, and hierarchical issues. In like manner, it is more reasonable in assessing a cloud adoption undertaking to consider past the specialized features. Other research demonstrate exists which mean to cross over any barrier between the business and technical approaches and attempt to utilize perceived monetary models for adoption of CC [11]. To 
completely understand the choices with respect to the technical advancement appropriation, a far-reaching extent of study is required, and the particular factors should be considered by development highlights [6]. Therefore, we propose hypotheses for context as follows,

H10: Top Management will have positive influence on cloud computing adoption.

H11: Organization Readiness will have positive influence on cloud computing adoption.

H12: IS Knowledge will have positive influence on cloud computing adoption.

H13: Malicious Insiders will have negative influence on cloud computing adoption.

\section{Environmental}

Organization work inside a natural setting which bring them openings and limitations. Despite the fact, the outside condition can furnish an organization with data, assets and innovation, it has directions and confinements on the stream of capital and data. In addition, the business condition inside which the business works is of key criticalness. Normally, condition factors influencing technological selection is generally comprehended as aggressive pressure, which is respected one basic factor for innovative client in SMEs. Environmental factor incorporates this three-setting government regulatory support, competitive pressure, business continuity and data recovery, which is the most influential factor for cloud adoption [46].

H14: Government Regulatory Support will have positive influence on cloud computing adoption.

H15: Competitive Pressure will have positive influence on cloud computing adoption.

\section{Control Variable}

The review of the literature has demonstrated that some factors need to be controlled. These include respondents firm size and industry sectors. An organizations ability to adopt a cloud may also be influenced by its size. It is basic to see the utilization of control variable in data frameworks studies since they are utilized to control the variety of information that were not caught by the expressive factors. The previous writing has shown that a few elements should be controlled. These incorporate respondents size, industry verity. An association's capacity to embrace a cloud may likewise be impacted by its size. It is, for the most part, trusted that bigger enterprise has more noteworthy assets. Generally believed that larger enterprise possesses greater resources [56] then SMEs. What's more, attempt from various businesses may be influenced by numerous method for reception. Sorts of the business division in which the association is working are subsequently controlled for customers setting. Furthermore, cloud customers characteristics additionally can be utilizing a most moderate factor for cloud adoption and cloud security [30].

H16: Size will have positive influence on cloud computing adoption.
H17: Industry Type will have positive influence on cloud computing adoption.

\section{E. Questionnaires and Validations Design}

The proposed questionnaire form was depended on the variables. Each variable contains relevant questions to support the proposed enhancement model. In order to evaluating the elements in the questionnaire form, the Likert Scale was applied to have assessment and providing quantitative results for elements of items into data analysis process.

We have selected two IT company one small and one medium company as the case study. We created questionnaires and send them for their feedback. In this phase, all data that has been gathered was analyzed by using SPSS. Cronbach's Alpha was used in the analysis to test the data reliability [21]. The relationship between the construct is tested using Pearson's Correlation and Multiple Regression. Only IT personal and involve with the IT department people will be participating in the questionnaires specifically. Reliability is the ability of a measurement instrument to provide the same error-free results consistently. In other words, reliability is concerned with how much random error there is in the measurement. Cronbach's alpha $(\alpha)$ coefficient is commonly used by researchers [20, 26, 42, 50, 57] in this area and is recommended as a measure of internal consistency. It measures how closely a set of items is related to each other as a group [47]. A reliability coefficient of 0.70 or higher is considered acceptable in many research $[15,50]$. Cronbach's alpha $(\alpha)$ was used to access the reliability of items and $(\alpha)>$ 0.70 was used as the cut-off point items for each of the research factors.

\section{VII.DATA ANALYSIS}

\section{A. Questionnaire Section A: Demographic}

Questionnaires are typically used for feedback research to determine the current status or situation [29]. Designing a survey questionnaire is one of the most critical stages in research. It was essential that respondents must adopt cloud services in their SME and continue using it. Therefore, in order to find this sort of participant, it was searched in the net and SMEs was chosen based on the conditions that must be interested in using cloud-based services and they are using SaaS as public cloud platform in their enterprises and number of employees that must have, because of the scope of this study for SMEs. This research had 53 respondents from two IT company and Information Security Students which all the respondents were IT, cloud related personals. The aim of this section is to gain information about the demographic particulars of the respondents involved in this research. The demographic details included the respondent's details (gender, age, education, and his/her role at the firm).

As analysis show everyone use SaaS service layer who are participated to the survey. In total 53 responders are using Software as a Service (SaaS) layer for their service in this 
study $(100 \%)$ as the research focused on the SaaS layer. And, the cloud deployed model according to the participants which type of cloud they are using. Everyone is working on 'Public Cloud', which reflects on responses of total 53 participants $(100.0 \%)$. We studied on this IT budget fields. We can see from the participants review for company shows high percentages is $20-40 \%$ of total budget is for cloud as this is one of the most important factors for SMEs snow a day which is $60.4 \%$. Now more Some participants think it is more like $50 \%$ to more as small companies only depends on the cloud service like (Software as a Service) they don't need any infrastructure.

\section{B. Descriptive Statistics of the Variables}

In the technological factor of TOE model shows mostly the cloud security factors for SMEs. This research questions support the security aspects by descriptive analysis using IBM Statistics SPSS v22 shows the aspects for explains that the mean range 4.54 to 4.60 while the median range 4.99 to 5.0. Secondly, the standard deviation range 0.631 to 0.652 while total number of the responses is 53 which proves that there were no missing data value.

In the Organization variables of TOE model shows which part is influential organization factors for security perspective for SMEs shows the aspects for explains that the mean range 4.55 to 4.62 while the median 5.0. Secondly, the standard deviation range 0.596 to 0.617 while total number of the responses is 53 which proves that there were no missing data value.

In the Environmental variables of TOE model shows which part is influential factors for security perspective for SMEs shows the aspects for explains that the mean range 4.54 to 4.55 while the median 5.0. Secondly, the standard deviation range 0.6 .31 to 0.652 while total number of the responses is 53 which proves that there were no missing data value.

In the Control Variables of TOE model shows which part is influential factors for security perspective for SMEs shows the aspects for explains that the mean range with in 4.58 while the median range in 5.0. Secondly, the standard deviation range 0.595 to 0.603 while total number of the responses is 53 which proves that there were no missing data value.

\section{Reliability Test}

In this case, the analysis (TABLE I) shows that most of the variable show high data reliability which is above 0.7 , except Control Variable and final cloud adoption which has the lower value than 0.7 , which is 0.51 respectively. However, the overall reliability for all items is at 0.764 .
TABLE I. I LIABILITY STATISTICS ITEM

\begin{tabular}{|c|c|c|c|}
\hline Variable & $\begin{array}{c}\text { Cranach's } \\
\text { Alpha }\end{array}$ & $\begin{array}{c}\text { Number of } \\
\text { Items }\end{array}$ & Mean \\
\hline Technological(T) & 0.95 & 109 & 4.55 \\
\hline Organizational(O) & 0.86 & 44 & 4.58 \\
\hline Environmental(E) & 0.73 & 16 & 4.55 \\
\hline Control Variable (CV) & 0.51 & 16 & 4.58 \\
\hline Overall & 0.764 & 185 & 4.57 \\
\hline
\end{tabular}

\section{Correlations Test}

After correlations analysis we found, according to TABLE II, there is two hypotheses:

TABLE II. CORRELATIONS SUMMARY

\begin{tabular}{|c|c|c|c|c|c|c|}
\hline & & $T$ & $\boldsymbol{O}$ & $E$ & $C V$ & $C A D$ \\
\hline \multirow{3}{*}{$\mathrm{T}$} & $\begin{array}{l}\text { Pearso } \\
\mathrm{n} \\
\text { Correl } \\
\text { ation }\end{array}$ & 1 & $.618^{* *}$ & $.545^{* *}$ & $.618^{* *}$ & $.302^{*}$ \\
\hline & $\begin{array}{l}\text { Sig. } \\
(2- \\
\text { tailed) }\end{array}$ & & .000 & .000 & .000 & .028 \\
\hline & $\mathrm{N}$ & 53 & 53 & 53 & 53 & 53 \\
\hline \multirow{3}{*}{$\mathrm{O}$} & $\begin{array}{l}\text { Pearso } \\
\mathrm{n} \\
\text { Correl } \\
\text { ation }\end{array}$ & $\begin{array}{r}.618^{*} \\
*\end{array}$ & 1 & $.738^{* *}$ & $.627^{* *}$ & $.349^{*}$ \\
\hline & $\begin{array}{l}\text { Sig. } \\
(2- \\
\text { tailed) }\end{array}$ & .000 & & .000 & .000 & .010 \\
\hline & $\mathrm{N}$ & 53 & 53 & 53 & 53 & 53 \\
\hline \multirow{3}{*}{$\mathrm{E}$} & $\begin{array}{l}\text { Pearso } \\
\mathrm{n} \\
\text { Correl } \\
\text { ation }\end{array}$ & $.545^{*}$ & $.738^{* * *}$ & 1 & $.827^{* *}$ & .107 \\
\hline & $\begin{array}{l}\text { Sig. } \\
(2- \\
\text { tailed) }\end{array}$ & .000 & .000 & & .000 & .446 \\
\hline & $\mathrm{N}$ & 53 & 53 & 53 & 53 & 53 \\
\hline \multirow{3}{*}{$\mathrm{CV}$} & $\begin{array}{l}\text { Pearso } \\
\mathrm{n} \\
\text { Correl } \\
\text { ation }\end{array}$ & $.618^{*}$ & $.627^{* * *}$ & $.827^{* * *}$ & 1 & .129 \\
\hline & $\begin{array}{l}\text { Sig. } \\
(2- \\
\text { tailed) }\end{array}$ & .000 & .000 & .000 & & .358 \\
\hline & $\mathrm{N}$ & 53 & 53 & 53 & 53 & 53 \\
\hline \multirow{3}{*}{$\begin{array}{c}\text { CA } \\
\text { D }\end{array}$} & $\begin{array}{l}\text { Pearso } \\
\mathrm{n} \\
\text { Correl } \\
\text { ation }\end{array}$ & $.302^{*}$ & $.349^{*}$ & .107 & .129 & 1 \\
\hline & $\begin{array}{l}\text { Sig. } \\
(2- \\
\text { tailed) }\end{array}$ & .028 & .010 & .446 & .358 & \\
\hline & $\mathrm{N}$ & 53 & 53 & 53 & 53 & 53 \\
\hline
\end{tabular}


Technological and Organizational factor ( $\mathrm{r}$ value >0.30) have strong correlation relationship with Cloud adoption as this two are showing the most relevant factors for cloud adoptions security aspects. While the other hypotheses; Environmental and Control Variable have modest relationship with Cloud Adoption.

According to the previous TABLE II, the correlation process of cloud adoption TOE model for the cloud security influential factors in SMEs companies among all variables, the highest coefficient ( $\mathrm{r}$ value) correlations are Competitive Pressure, IS knowledge, service level agreement and other are moderate strength of relationship like Cloud security, Malicious Insiders, Company Capability, Government Regulatory Support, Related Advantages, Cost Saving ,Top Management ,Company Size and Company Type, Trust and Lack of IT Cloud Standards; while a Weak correlation ( $r$ value is .278) Organization Readiness remaining between variables (shows in Fig. 4).

\section{E. Regression}

The regressions analysis used to test the relationships among entire variables on the dependent variable. In this study, multiple regressions are used to determine the best linear combination of technological, organizational, environmental, control variable. TABLE III shows that the R2 $=0.756$.

TABLE III.

REGRESSION MODEL SUMMARY

\begin{tabular}{l|r|r|r|r|}
\hline Model & $\boldsymbol{R}$ & $\boldsymbol{R}$ Square & $\begin{array}{c}\text { Adjusted } \boldsymbol{R} \\
\text { Square }\end{array}$ & $\begin{array}{c}\text { Std. } \text { Error of the } \\
\text { Estimate }\end{array}$ \\
\hline 1 & $.869^{\mathrm{a}}$ & .756 & \multicolumn{2}{|c|}{.637} \\
\hline
\end{tabular}
Predictors: (Constant), VINT, TAV, EGRS, TSLA, OOR, ECP, OTM, VINS, TCOS,
TCS, TTR, TCAP, TLS, TRA, OIS, TCT, OMI

It can be seen that the adjusted $\mathrm{R}$ square value for the regression model is .637 , which means that in this model $63.7 \%$ of variances on cloud adoption are explained by the independent variable collectively, and the significance value of the regression model is .000 (see TABLE IV) which means that independent variables involved in this model collectively have a significant correlation with the dependent variable, which is cloud adoption.

\section{TABLE IV. ANOVAA RESULT}

\begin{tabular}{|l|l|r|r|r|r|r|}
\hline \multicolumn{2}{|c|}{ Model } & $\begin{array}{c}\text { Sum of } \\
\text { Squares }\end{array}$ & Df & $\begin{array}{c}\text { Mean } \\
\text { Square }\end{array}$ & \multicolumn{1}{c|}{ F } & \multicolumn{1}{c|}{ Sig. } \\
\hline \multirow{4}{*}{1} & $\begin{array}{l}\text { Regressi } \\
\text { on }\end{array}$ & 1.455 & 17 & .086 & 6.377 & $.000^{\mathrm{b}}$ \\
\cline { 2 - 7 } & Residual & .470 & 35 & .013 & & \\
\cline { 2 - 7 } & Total & 1.925 & 52 & & & \\
\hline
\end{tabular}

The coefficients analysis expounds the relationship among the regression independent variables against the dependent variable. The size of every variable can affect by the dependent variable. The rising of each variable unit affects the dependent variable due to all the variables are not changed. The following table describes the coefficients among variables as following TABLE V.

\section{F. Hypothesis Testing}

For testing the hypotheses, from TABLE V this study used regressions to analyses the seventeen hypotheses formulated at the conceptual TOE model; seventeen were confirmed to have relationship with cloud adoption (TABLE V). But according to the regression result, $\beta=0.077, p<0.05$, Cloud Security does have positive relationship with Technological factor not negative relations as we assumed in Hypothesis. Technology Readiness, Trust and Lack of standards have negative relations ship with technology factor $(\beta=-0.022, \beta=-0.041, \beta$ $=-0.152)$. And also found out Malicious insider have positive relations ship with the organizations factor $(\beta=.342)$ in terms of security influential factor analysis (shows in Fig. 4).

\section{TABLE V. COEFFICIENTS SUMMARY}

\begin{tabular}{|c|c|c|c|c|c|c|}
\hline \multirow[t]{2}{*}{ Model } & & \multicolumn{2}{|c|}{$\begin{array}{l}\text { Unstandardized } \\
\text { Coefficients }\end{array}$} & \multirow{2}{*}{$\begin{array}{l}\text { Stand } \\
\text { ardize } \\
\text { d } \\
\text { Coeffi } \\
\text { cients }\end{array}$} & \multirow[t]{2}{*}{$t$} & \multirow[t]{2}{*}{ Sig. } \\
\hline & & $\boldsymbol{B}$ & $\begin{array}{l}\text { Std. } \\
\text { Error }\end{array}$ & & & \\
\hline \multirow{10}{*}{ Technological } & $\begin{array}{l}\text { (Cons } \\
\text { tant) }\end{array}$ & -1.568 & 0.524 & & -2.992 & 0.005 \\
\hline & TCS & 0.077 & 0.11 & 0.086 & 0.705 & 0.485 \\
\hline & TRA & 0.407 & 0.118 & 0.379 & 3.448 & 0.001 \\
\hline & $\begin{array}{l}\text { TCO } \\
\text { S }\end{array}$ & 0.097 & 0.09 & 0.103 & 1.075 & 0.288 \\
\hline & TAV & 0.057 & 0.074 & 0.059 & 0.773 & 0.444 \\
\hline & $\begin{array}{l}\text { TSL } \\
\text { A }\end{array}$ & 0.701 & 0.133 & 0.521 & 5.257 & .000 \\
\hline & TTR & -0.022 & 0.107 & -0.024 & -0.209 & 0.835 \\
\hline & TCT & -0.041 & 0.113 & -0.041 & -0.365 & 0.717 \\
\hline & $\begin{array}{l}\text { TCA } \\
\mathrm{P}\end{array}$ & 0.196 & 0.099 & 0.211 & 1.972 & 0.055 \\
\hline & TLS & -0.152 & 0.114 & -0.146 & -1.336 & 0.189 \\
\hline \multirow{5}{*}{ Organizational } & $\begin{array}{l}\text { (Cons } \\
\text { tant) }\end{array}$ & -.241 & .492 & & -.490 & .626 \\
\hline & OTM & .220 & .090 & .220 & 2.450 & .018 \\
\hline & OOR & .065 & .087 & .062 & .746 & .460 \\
\hline & OIS & .430 & .089 & .469 & 4.834 & .000 \\
\hline & OMI & .342 & .090 & .332 & 3.808 & .000 \\
\hline
\end{tabular}




\begin{tabular}{|l|l|l|l|l|l|l|}
\hline \multirow{5}{*}{ Environmental } & $\begin{array}{l}\text { (Cons } \\
\text { tant) }\end{array}$ & -.150 & .364 & & -.414 & .681 \\
\cline { 2 - 7 } & $\begin{array}{l}\text { EGR } \\
\mathrm{S}\end{array}$ & .371 & .076 & .378 & 4.907 & .000 \\
\cline { 2 - 7 } & $\mathrm{ECP}$ & .657 & .081 & .626 & 8.116 & .000 \\
\hline \multirow{3}{*}{$\begin{array}{l}\text { Control } \\
\text { Variable }\end{array}$} & $\begin{array}{l}\text { (Cons } \\
\text { tant) }\end{array}$ & .145 & .711 & & .204 & .839 \\
\cline { 2 - 7 } & VINS & .526 & .115 & .495 & 4.568 & .000 \\
\cline { 2 - 7 } & VINT & .434 & .136 & .346 & 3.191 & .002 \\
\hline
\end{tabular}

TABLE VI. HYPOTHESIS STATUS AFTER ANALYSIS

\begin{tabular}{|l|c|c|}
\hline Hypotheses & Correlation & Result \\
\hline Hypothisis1 & Moderate & Supported \\
\hline Hypothisis2 & Moderate & Supported \\
\hline Hypothisis3 & Moderate & Supported \\
\hline Hypothisis4 & Moderate & Supported \\
\hline Hypothisis5 & High & Supported \\
\hline Hypothisis6 & Moderate & Supported \\
\hline Hypothisis7 & Moderate & Supported \\
\hline Hypothisis8 & Moderate & Supported \\
\hline Hypothisis9 & Moderate & Supported \\
\hline Hypothisis10 & Moderate & Supported \\
\hline Hypothisis11 & Low & Supported \\
\hline Hypothisis12 & High & Supported \\
\hline Hypothisis13 & Moderate & Supported \\
\hline Hypothisis14 & Moderate & Supported \\
\hline Hypothisis15 & High & Supported \\
\hline Hypothisis16 & Moderate & Supported \\
\hline Hypothisis17 & Moderate & Supported \\
\hline
\end{tabular}

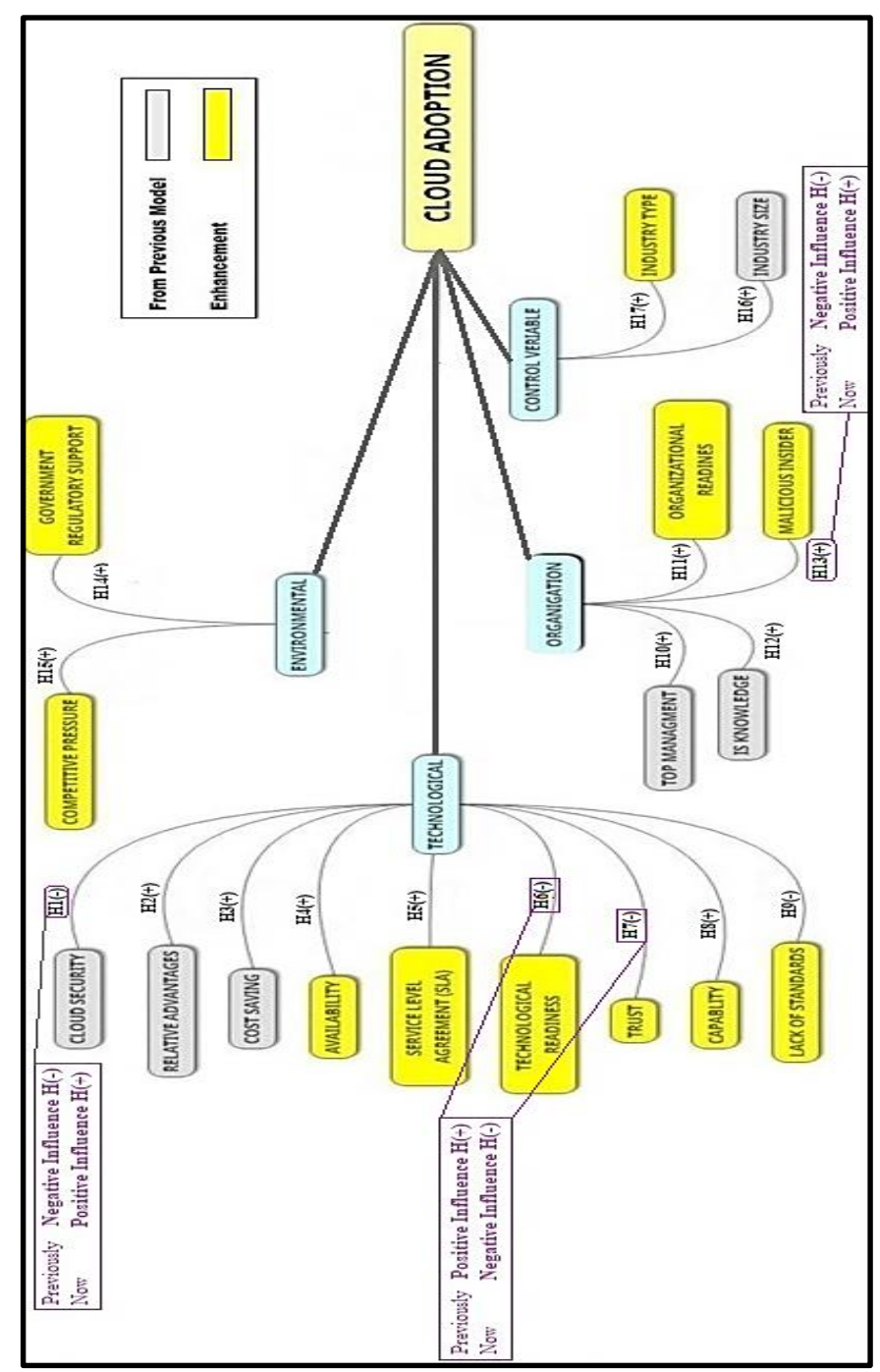

Fig. 4. Final Research (Enhance TOE) Model

\section{DISCUSSION}

Based on the existing literature on technology adoption, we focused on CC security in this research. 
This chapters also identify a lack of available well-defined and well-framed research on factors to find out the influencing factors for cloud adoption in terms of cloud security factors. Based on objectives of this study, the influential factors of the cloud adoption among SMEs in term of security aspects have been identified (TABLE VI). Through literature review, the model for Cloud Adoption for SMEs in terms of security influential factors was developed, with technological, organizational, environmental and control variable. And the model has been evaluated through questionnaire, analyzed and validate by using correlation and regression methods (Fig. 4).

In this portion we present the research limitation, as every research go through certain conditions and limitation. These limitations are as follows:

1. This research mainly focusses on the cloud adoption influential factor concept, with using assessment technic using TOE model for cloud security. So, we mainly work on the security aspects of the cloud. So, we don't work outside of this boundary.

2. This paper focus on the SMEs for cloud adoption factors, we did not work on big organization.

3. This research work on only two IT companies only. Future research can be done with more SMEs.

4. This research work on questionnaire and work on only 53 response and more than 182 questions.

5. On this paper its use TOE model for assessing the cloud adoptions security. But to make this research stronger other researcher can work with the other technology adoption model to enrich the concept.

6. Here in this study it is using case study questionnaires for evaluating the proposed enhancement of the model. And in future researcher can use different evaluation method to determine more promising way to appraise the result.

7. For result used IBM Statistics SPSS v22. Nevertheless, there are other process can be used for result.

8. We will be using only 37 previous TOE models to achieve the objectives.

In this research contribution and contribution part, this study is totally focused on the cloud adoption and its influencing factors, by using TOE model and using its advantages for propose an improved model so that it can investigate on the cloud security influential factors for cloud adoption. By using this study recommendation, they will get a clear guidance that which factors and elements they need to understand about cloud security, so it will be so easy for the cloud customer to focus on their business rather than technological infrastructures.

This research provided one of a kind investigation and recommendation for cloud security and cloud customer to appreciate more and eliminate the hesitation with easy guideline. By this study cloud customer can select and understand the cloud security and the significant aspects and which part they need recognize for cloud adoption.
In order to improve the results of the study in the future, improvements could be made to the study. The model can possibly be enhanced by considering more element and factors that can influence SMEs cloud adoptions. As I get feedback from the SMEs companies can be work as future directions of this research. Company participants suggested that, the enhancement in TOE model needs to focus on the real environment and realistic security issues can be introduced for more deep understandings about cloud adoptions in security perspective also can be work in future studies. As the research worked on two SMEs company, for future researcher can use more SMEs for more perfect analysis result. As framework or model can be integrated with another model like TAM, DOI etc. Expand the research scope, covering more SMEs population in other area to improve the reliability of the results.

\section{CONCLUSION}

This provide the summary of the total research project by pointing out the limitation, recommendation and contribution of the project. This project approaches will show the persuasive factors of cloud security to the cloud customer in terms of cloud computing and appreciate clearly about the cloud security more simple way.

In conclusion, the factors that influence SMEs in terms of cloud adoption have been identified. Technological, Organizational and Environmental related to SMEs are the significant factors that influence cloud security factors. This result show that security threats towards cloud and indecision problem of SMEs can be mitigated or reduced by providing enhancement of TOE model showing concern to SMEs. The result of the study also shows some consistencies with the previous studies in the literature review. Where, cloud security, relative advantages, cost saving, availability, service level agreement, technological readiness, cloud trust, capability, lack of standards, top management, organizational readiness, IS knowledge, malicious insiders, government regulatory support, competitive pressure, industry size, and industry type are influential factors to the cloud security prospective in cloud adoptions for SMEs.

\section{ACKNOWLEDGMENT}

The authors would like to acknowledge the research is supported by two SME company (one ISP internet provider medium company called BrakNet from Bangladesh and another one is web hosting small company name Hostmywebsitenow.com from India) by conducted data analysis in collaboration. 


\section{REFERENCES}

[1] Ahmed, M., \& Mahbub. (2013). Trust Enhanced Security In Saas Cloud Computing By Access To Thesis - A. Retrieved From Http://Dro.Deakin.Edu.Au/View/Du:30063020

[2] Al, S. (2016). Cloud Computing Adoption Determinants: An Analysis of Australian SMEs Cloud Computing Adoption Determinants: An Analysis of Australian SMEs, 1-17. Retrieved from http://ro.uow.edu.au/cgi/viewcontent.cgi?article $=6855 \&$ context $=$ eispapers.

[3] Aldossary, S., \& Allen, W. (2016). Data Security, Privacy, Availability and Integrity in Cloud Computing: Issues and Current Solutions. International Journal of Advanced Computer Science and Applications, 7(4): 485-498.

[4] Alshamaila, Y., Papagiannidis, S. \& Stamati, T. 2013. Cloud Computing Adoption In Greece. Proceedings of UK Academy for Information Systems Conference, 1-17.

[5] Andrikopoulos, V., Binz, T., Leymann, F., Strauch, S. (2013). How to Adapt Applications for the Cloud Environment. Computing, 95(6): 493-535.

[6] Asiaei, A., Zairah, N., \& Rahim, A. (2016). Conceptualizing a Model for Cloud Computing Adoption by Smes. Retrieved from http://ais.utm.my/paris2016/files/2016/11/21Conceptualizing-a-Model-for-Cloud-Computing-Adoption-bySMEs.pdf.

[7] Baars, M. J. H., Henneman, L., \& ten Kate, L. P. (2005). Deficiency of Knowledge of Genetics and Genetic Tests among General Practitioners, Gynecologists, and Pediatricians: A Global Problem. Genetics in Medicine, 7(9), 605-610.

[8] Beulah, S., \& Ramesh Dhanaseelan, F. (2016). Survey on Security Issues and Existing Solutions in Cloud Storage. Indian Journal of Science and Technology, 9(13). https://doi.org/10.17485/ijst/2016/v9i13/90588.

[9] Bouchenak, S. (2010). Automated Control for SLA-aware Elastic Clouds. Proceedings of the Fifth International Workshop on Feedback Control Implementation and Design in Computing Systems and Networks, ACM, New York.

[10] Carvalho, C. A. B. de, Andrade, R. M. de C., Castro, M. F. de, Coutinho, E. F., \& Agoulmine, N. (2016). State of the art and Challenges of Security SLA for Cloud Computing. Computers and Electrical Engineering, 1-12. https://doi.org/10.1016/j.compeleceng.2016.12.030.

[11] Chang, V., \& Ramachandran, M. (2016). Towards Achieving Data Security with the Cloud Computing Adoption Framework. IEEE Transactions on Services Computing, 9(1), 138-151. https://doi.org/10.1109/TSC.2015.2491281.

[12] Chau, P. Y. K., Tam, K. Y. (1997) Factors Affecting the Adoption of Open Systems: An Exploratory Study. MIS Q, 21: $1-24$

[13] Chawngsangpuii, R., \& Das, R. K. (2014). A Challenge for Security and Service Level Agreement in Cloud Computinge, 2319-2322.

[14] Choudhary, V. (2007). Software as a Service: Implications for Investment in Software Development. International Conference on System Sciences, 209.

[15] Cohen, J. F., Mou, J. \& Trope, J. (2014). Adoption of Cloud computing by South African Firms: The Role of Institutional Forces, Absorptive Capacity, and Top Management, Proceedings of the Southern African Institute for Computer Scientist and Information Technologists Annual Conference 2014 on SAICSIT 2014 Empowered by Technology, 30.
[16] Dillon, S., \& Vossen, G. (2009). SaaS Cloud Computing in Small and Medium Enterprises: A Comparison between Germany and New Zealand, (Mather), 1-16. https://doi.org/10.1504/IJITCC.2015.070998.

[17] Fernandes Yun Chi, Hyun Jin Moon, Hakan Hacigumus And Junichi Tatemura. (2011). Sla - Tree: A Framework for Efficiently Supporting Sla-Based Decisions in Cloud Computing. Proceedings of the 14th International Conference on Extending Database Technology, 129-140.

[18] Fernandes, D. A., B. Soares, Liliana. F., B. Gomes, João, V. Freire, Mário. M., Inácio, P. R. M. (2014). Security Issues in Cloud Environments: A Survey. International Journal of Information Security, 13(2): 113-170.

[19] Forbes.com. (2017). Forbes Welcome. [online] Available at: https://www.forbes.com/sites/louiscolumbus/2017/02/18/rights cale-2017-state-of-the-cloud-report-azure-gaining-inenterprises/\#32a1546b8481 [Accessed 18 Feb. 2017].

[20] Hair, J. F., Hult, G. T. M., Ringle, C. and Sarstedt, M. 2013. A Primer on Partial Least Squares Structural Equation Modeling (PLS-SEM). SAGE Publications, Inc.

[21] Hossain, S., Independent, A., Location, I. N., Framework, T., \& Access, O. (2012). Universiti Teknologi Malaysia Declaration of Thesis/Undergraduate Project Paper and Copyright Application Independent in Location Sufficient in Terms of Scope and Quality for the Award of the Degree of Master of Signature Date Signature Name of Supervis, 16(February).

[22] Hussein, N. H., \& Khalid, A. (2016). A Survey of Cloud Computing Security Challenges and Solutions. International Journal of Computer Science and Information Security, 14(1), 52-56. Retrieved from https://www.cse.wustl.edu/ jain/cse57015/ftp/cld_sec.pdf.

[23] Kalaiprasath, R., Elankavi, R., \& Udayakumar, R. (2017). A Cloud Security and Compliance-A Semantic Approach in End to End Security. International Journal Of Mechanical Engineering and Technology (Ijmet), 8(5): 482-494. Retrieved from

https://www.exeley.com/exeley/journals/in_jour_smart_sensing _and_intelligent_systems/10/4/pdf/10.21307_ijssis-2017_ 265.pdf.

[24] Kim, W., Kim, S. D., Lee, E. \& Lee, S. (2009). Adoption Issues for Cloud Computing. Proceedings of MoMM2009, ACM, Kuala Lumpur, Malaysia.

[25] Kuan, K. K. Y., \& Chau, P. Y. K. (2001). A Perception-based Model for Edi Adoption in Small Businesses Using a Technology-organization-environment Framework. Journal of Information and Management, 38(8): 507-521.

[26] Lee, J. S. \& Kwon, Y. (2014). Exploring Key Factors of Application Software Services and Their Relationships for Organizational Success in SMEs'. Journal of Small Business Management. 52(4): 753-70.

[27] Lewandowski, J., Salako, A. O., \& Garcia-Perez, A. (2013). SaaS Enterprise Resource Planning Systems: Challenges of Their Adoption in SMEs. 2013 IEEE 10th International Conference on E-Business Engineering, (September), 56-61. https://doi.org/10.1109/ICEBE.2013.9.

[28] Lin, H. F.. and Lin, S. M. (2008). Determinants of e-business Diffusion: A Test of the Technology Diffusion Perspective. Technovation, 28(3): 135-145.

[29] Linlin Wu and Rajkumar Buyya. (2010). Service Level Agreement (SLA) in Utility Computing Systems. Technical Report CLOUDS-TR-2010-5, Cloud Computing and Distributed Systems Laboratory, The University of Melbourne, Australia. 
[30] Low, C., Chen, Y. and Wu, M. (2011). Understanding the Determinants of Cloud Computing Adoption. Industrial Management \& Data Systems, 111(7): 1006-1023.

[31] M. Alhamad, T. Dillon and E. Chang. (2010). Conceptual Sla Framework for Cloud Computing. Australia, Http://Ieeexplore.Ieee.Org/Xpl/Login.Jsp?Tp=\&Arnumber=561 $0586 \& \mathrm{Url}=\mathrm{Http} \% 3 \mathrm{a} \% 2 \mathrm{f} \% 2$ fieeexplore.Ieee. Org\%2fxpls\%2fabs_All.Jsp\%3farnumber\%3d5610586.

[32] Mangula, I. S., Van De Weerd, I., \& Brinkkemper, S. (2014). The Adoption of Software-as-Service: An Indonesian Case Study. Association for Information Systems Ais Electronic Library (Aisel). Retrieved From Http://Aisel.Aisnet.Org/Pacis2014.

[33] Marston, S., Li, Z., Bandyopadhyay, S., Zhang, J. \& Ghalsasi, A. (2011). Cloud Computing - The Business Perspective. Decision Support Systems, 51: 176-189.

[34] Mell, P., and Grance, T. (2009a). Effectively and Securely Using the Cloud Computing Paradigm, Ver.26, Http://csrc.nist.gov/groups/SNS/cloud-computing/cloudcomputing-v26.ppt, last visited on 15, May 2012.

[35] Mladenow, A., Fuchs, E., Dohmen, P. and Strauss, C. (2012). Value Creation using Clouds, Analysis of Value Drivers for Start-Ups and Small and Medium Sized Enterprises in the Textile Industry. 26th International Conference on Advanced Information Networking and Applications Workshops.

[36] Nkhoma, M. Z., Dang, D. P. T., \& De Souza-Daw, A. (2013). Contributing Factors of Cloud Computing Adoption: A Technology-Organization-Environment framework approach. International Conference on Information Management and Evaluation, 180-188.

[37] P. F. Hsu, K. L. Kraemer, D. Dunkle. (2006). Determinants of e-business Use in US Firms. Int. J. Electr. Commer., 10: 9-45.

[38] Pankesh Patel, Ajith Ranabahu and Amit Sheth. (2009). Service Level Agreement in Cloud Computing. Report, Core Wright University Libraries, Kno.e.sis Publications.

[39] Pawar, P. S. (2015). Cloud Broker Based Trust Assessment of Cloud Service Providers. Retrieved from http://openaccess.city.ac.uk/13687/.

[40] Pearson, S. (2013). Privacy, Security and Trust in Cloud Computing. Privacy and Security for Cloud Computing. Springer, 3-42.

[41] Phaphoom, N., Wang, X., Samuel, S., Helmer, S., Abrahamsson, P. (2015). A Survey Study on Major Technical Barriers Affecting the Decision to Adopt Cloud Services. J Syst Softw, 103: 167-181.

[42] Prasad, A., Green, P., Heales, J. \& Finau, G. (2014a). Towards a Model of Cloud Computing Services for SMEs'. 25th Australasian Conference on Information Systems, Auckland, New Zealand.

[43] R. Bose, X. Luo. (2011). Integrative Framework for Assessing Firms' Potential to Undertake Green IT Initiatives Via Virtualization - A Theoretical Perspective, J. Strat. Inf. Syst., 20: 38-54.

[44] Ruwan, \& Ruwansenarathna, R. (2016). Cloud Computing Adoption by Smes in Australia, (February). Retrieved From Http://Dro.Deakin.Edu.Au/View/Du:30088887.
[45] Salwani, M. I., Marthandan, G., Norzaidi, M. D. and Chong, S. C. (2009). E-commerce Usage and Business Performance in the Malaysian Tourism Sector: Empirical Analysis. Information Management \& Computer Security, 17(2), 166-185.

[46] Schnjakin, M., Alnemr, R., \& Meinel, C. (2010, October). Contract-based Cloud Architecture. CloudDB"10 Proceedings of the Second International Workshop on Cloud Data Management, Toronto, Ontario, Canada, 33-40.

[47] Straub, D. W. (1989). Validating Instruments in MIS Research. MIS Quarterly, 13(2): 147-69.

[48] Tan, M., Tc, T., \& Margaret, L. (2012). Exploring Organisational Adoption of Cloud Computing in Singapore. Proceedings of the 19th ITS Biennial Conference 2012 Bangkok, Thailand. 1-21. Retrieved from http://hdl.handle.net/10419/72509.

[49] Tariq, M. I., Haq, I. U., \& Iqbal, J. (2013). SLA Based Information Security Metric for Cloud Computing from COBIT 4.1 Framework. International Journal of Computer Networks and Communications Security, 1(3), 95-101. Retrieved from www.ijencs.org.

[50] Tehrani, S. R. and Shirazi, F. (2014). Factors Influencing the Adoption of Cloud Computing by Small and Medium Size Enterprises (Smes). Human Interface and the Management of Information. Information and Knowledge in Applications and Services. Springer

[51] Tornatzky, L. G. and Fleischer, M. (1990). The Processes of Technological Innovation. Lexington Books, Lexington, MA.

[52] Vadapalli, A. \& Ramamurthy, K. (1997). Business Use of the Internet: An Analytical Framework and Exploratory Case Study. International Journal of Electronic Commerce, 2(2): 7194.

[53] Vatanasakdakul, S., Aoun, C., \& Chen, Y. Nicole. (2017). Chasing Success: An Empirical Model for IT Governance Frameworks Adoption in Australia. Science, Technology and Society, 22(2): 182-211. https://doi.org/10.1177/0971721817702278.

[54] Wikipedia, Wikimedia Foundation. (2017). Cloud Computing Security.

En.Wikipedia.Org/Wiki/Cloud_Computing_Security\#Cite_Not e-3.

[55] Wu, L. (2014). Sla-Based Resource Provisioning for Management of Cloud-based Software-as-a-Service Applications. Retrieved From Https://MinervaAccess.Unimelb.Edu.Au/Handle/11343/41013.

[56] Young, R., \& Poon, S. (2013). Top Management SupportAlmost Always Necessary and Sometimes Sufficient for Success: Findings from a Fuzzy Set Analysis. International Journal of Project Management, 31(7): 943-957.

[57] Zhao, F., Scheruhn, H-J., \& von Rosing, M. (2014). The Impact of Culture Differences on Cloud Computing Adoption. HumanComputer Interaction: Applications and Services, Springer, 776-85.

[58] Zhu, K., Kraemer, K.L., Xu, S. and Dedrick, J. (2004). Information Technology Payoff in E-Business Environments: an International Perspective on Value Creation of E-Business in the Financial Services Industry. Journal of Management Information Systems, 21: 17-54. 